\title{
Section introduction Risk factors. Introduction to Session 1
}

\author{
Anthony Howell ${ }^{1}$ and Jack Cuzick ${ }^{2}$
}

\begin{abstract}
${ }^{1}$ The University of Manchester, The Christie NHS Foundation Trust, Paterson Institute for Cancer Research, Wilmslow Road, Manchester, M20 4BX, UK ${ }^{2}$ Cancer Research UK Department of Epidemiology, Mathematics and Statistics, Queen Mary, University of London, Wolfson Institute of Preventive Medicine, Charterhouse Square, London, EC1M 6BQ, UK
\end{abstract}

Corresponding author: Anthony Howell, Anthony.Howell@christie.nhs.uk

Published: 18 December 2009

This article is online at

http://breast-cancer-research.com/supplements/11/S3/S2

\section{Risk factors}

Risk factors for any disease including breast cancer are important for at least two reasons. Once discovered, a verified risk factor may be associated with a reduction of the incidence of the disease if avoided (for example, alcohol). The majority of risk factors for breast cancer, however, are not avoidable in everyday life (for example, family history and age of menarche, first pregnancy and menopause). But these risk factors, including mammographic density, can be incorporated into models (for example, the Tyrer-Cuzick model) that enable better prediction of risk and targeting of preventive measures.

\section{Alcohol and breast cancer risk}

Peter Boyle summed up the considerable old and new evidence that alcohol is a risk factor for breast cancer. Recent reports - including the overview of the International Agency for Research on Cancer [1], the Million Women Study [2] and the Women's Health Study [3] - indicate that risk is increased by approximately $10 \%$ for one drink per day $(10 \mathrm{~g})$ and that there is a dose-response curve that appears linear and unrelated to whether alcohol is from wine or not. In France, it was estimated that $9.4 \%$ of all breast cancers could be attributable to alcohol. Boyle indicated that there were no data on risks after cessation of alcohol and the mechanism of alcohol-induced breast cancer was unclear except that one study suggested estrogen receptor-positive and progesterone receptor-positive cancers were involved, consistent with some form of hormonal mechanism [4].

\section{Breast density and breast cancer risk}

Norman Boyd summarised the relationship between breast density and breast cancer. A meta-analysis of the association between percentage mammographic density with risk of breast cancer in $>14,000$ cases and 226,000 non-cases from 42 studies [5] indicated that the increase in relative risk was fourfold to fivefold for high density versus low density, but Boyd thought the difference may increase to sevenfold to ninefold using the newer volume measurements of density.
Breast Cancer Research 2009, 11(Suppl 3):S2

(doi:10.1186/bcr2421)

(c) 2009 BioMed Central Ltd

He described several methods for measuring density (Wolfe categories, the Breast Imaging Reporting and Data System, visual methods and Cumulus): all of the current methods indicate risk - but all have advantages and disadvantages, and none is ideal. Mammographic density declines with age and pregnancies, weight, the menopause, tamoxifen use and lutenising hormone releasing hormone agonists, and greater density is associated with a family history and hormone replacement therapy use. It is estimated that two-thirds of the density is heritable. In the preventive setting, mammographic density added to the Gail model only gives a moderate increase in prediction [6].

\section{Cosmetics and breast cancer risk}

Phillipa Darbre reported on the evidence for a relationship between underarm antiperspirant/deodorant cosmetic use and breast cancer. She pointed out the association between greater incidence of breast cancer in the upper outer quadrant and the increasing use of underarm cosmetics. A causal relationship is supported by the estrogenicity of the compounds in in vitro cell assays (and the potential for mixtures to give greater doses) and by reports of greater genomic instability in cells from the upper outer quadrant [7]. Aluminum in antiperspirants is absorbed, can bind DNA, is estrogenic and is found in greater concentrations in the upper outer quadrant. A small study reported high concentrations of aluminum in type I breast cysts. All of the above data fulfill most of the Bradford-Hill criteria of association or causality. It will be important to determine whether the accumulated chemicals in the breast are bioactive and to devise new methods to prove causality.

\section{Competing interests}

The authors declare that they have no competing interests.

\section{Acknowledgement}

This article has been published as part of Breast Cancer Research Volume 11 Suppl 3 2009: Controversies in Breast Cancer 2009. The full contents of the supplement are available online at http://breastcancer-research.com/supplements/11/S3. 


\section{References}

1. Boffetta P, Hashibe M, La Vecchia C, Zatonski W, Rehm J: The burden of cancer attributable to alcohol drinking. Int J Cancer 2006, 119:884-887.

2. Allen NE, Beral V, Casabonne D, Kan SW, Reeves GK, Brown A, Green J; Million Women Study Collaborators: Moderate alcohol intake and cancer incidence in women. J Natl Cancer Inst 2009, 101:296-305.

3. Zhang SM, Lee IM, Manson JE, Cook NR, Willett WC, Buring JE: Alcohol consumption and breast cancer risk in the Women's Health Study. Am J Epidemio/ 2007, 165:667-676.

4. Lew JQ, Freedman ND, Leitzmann MF, Brinton LA, Hoover RN, Hollenbeck AR, Schatzkin A, Park Y: Alcohol and risk of breast cancer by histologic type and hormone receptor status in postmenopausal women: the NIH-AARP Diet and Health Study. Am J Epidemiol 2009, 170:308-317.

5. McCormack VA, dos Santos Silva I: Breast density and parenchymal patterns as markers of breast cancer risk: a meta-analysis. Cancer Epidemiol Biomarkers Prev 2006, 15: 1159-1169.

6. Chen J, Pee D, Ayyagari R, Graubard B, Schairer C, Byrne C, Benichou J, Gail MH: Projecting absolute invasive breast cancer risk in white women with a model that includes mammographic density. J Natl Cancer Inst 2006, 98:1215-1226.

7. Ellsworth DL, Ellsworth RE, Love B, Deyarmin B, Lubert SM, Mittal V, Hooke JA, Shriver CD: Outer breast quadrants demonstrate increased levels of genomic instability. Ann Surg Oncol 2004, 11:861-868. 